rev Psi

Revista de Psicología (UNLP)

https://revistas.unlp.edu.ar/revpsi

\title{
El saber sobre el autismo
}

\author{
Vilma Coccoz ${ }^{1,2}$ \\ Correspondencia \\ vilmacoccoz@gmail.com \\ Filiaciones institucionales \\ ${ }^{1}$ Escuela Lacaniana de Psicoanálisis (ELP, España) ${ }^{2}$ Asociación Mundial de Psicoanálisis (AMP).
}

\section{Resumen}

A partir de hitos en la historia de la clínica se enmarca el surgimiento del psicoanálisis como un discurso nuevo acerca de la causa de los padecimientos humanos (neurosis y psicosis) cuyo nódulo afecta a la identidad, a la cuestión del ser. La traducción de la obra de Freud a los saberes más avanzados llevada a cabo por Lacan ha permitido también la construcción de una práctica novedosa con los autistas que se ha desarrollado en el ámbito de la consulta y en las instituciones. Tomando como referencia el estudio de los testimonios de autistas y como resultado de una experiencia elaborada durante décadas se ha conseguido formular una orientación muy precisa de las intervenciones que facilitan el despliegue de la identidad, -en principio "borrosa" en el autista- teniendo en cuenta el estilo singular del borde que especifica su defensa. Esta perspectiva hace posible valorar la importancia creciente de la tecnotribu autista.

\section{Palabras clave}

identidad | diagnóstico estructural | clínica de la singularidad | tecnotribu autista

Coccoz, V. (2021). El saber sobre el autismo. Revista de Psicología, 20(1), 36-57. HTTPS://DX.DOI. ORG/10.24215/2422572XE115

\section{Proceso editorial}

Recibido

17 feb. 2021

Aceptado

12 may. 2021
1 ra decisión

12 may. 2021

Publicado

30 jul. 2021
Coordinadora del dossier

María Cristina Piro (Facultad de Psicología UNLP, Argentina).
ISSN

2422-572X

\section{Licencia}

Licencia de Cultura Libre CC-BY 4.0

(Compartir - Adaptar - Atribuir)

RevPsi es una publicación de la

Facultad de Psicología (Universidad

Nacional de La Plata, Argentina) 


\section{0 saber sobre 0 autismo}

\section{Resumo}

A partir de marcos na história da clínica, o surgimento da psicanálise é enquadrado como um novo discurso sobre a causa das doenças humanas (neurose e psicose) cujo nó afeta a identidade, a questão do ser. A tradução do trabalho de Freud no conhecimento mais avançado realizado por Lacan também permitiu a construção de uma nova prática com pessoas autistas que foi desenvolvida no campo da consulta e em instituições. Tomando como referência o estudo dos testemunhos de pessoas autistas e como resultado de uma experiência elaborada durante décadas, foi possível formular uma orientação muito precisa das intervenções que facilitam o desdobramento da identidade - em princípio "desfocada" na pessoa autistas - levando em conta o estilo singular da borda que especifica sua defesa. Esta perspectiva torna possível apreciar a crescente importância da tecnotribo autista.

\section{Palavras-chave}

identidade | diagnóstico estrutural | clínica de singularidade | tribo autista

\section{Knowledge about autism}

\section{Abstract}

Based on milestones in the history of the clinic, we frame the emergence of psychoanalysis as a new discourse on the cause of human suffering (neurosis and psychosis) whose node affects identity, the question of the self. The translation of Freud's work into the most advanced knowledge carried out by Lacan has also allowed the construction of a new practice with autistic people developed in consultation and institutions. Taking as a reference the study of the testimonies of autistic people and as a result of an experience developed over decades, it has been possible to formulate an exact orientation of the interventions that facilitate the unfolding of identity - in principle "blurred" in the autistic person - taking into account the singular style of the edge that specifies his or her defence. This perspective makes it possible to appreciate the growing importance of the autistic technotribe.

\section{Keywords}

identity | structural diagnosis | singularity clinic | autistic technotribe 
Hay personas para quien decir algunas palabras no es tan fácil. Se le llama autismo. (...) Simplemente son personas para quienes el peso de las palabras es muy serio y que no están fácilmente dispuestas a tomarlas a la ligera.

J. Lacan

En su libro, traducido al español con el título Yo pienso diferente, Josef Schovanec (2015) da a conocer su recorrido personal llegando a distinguirse como uno de los primeros autores franceses de "autibiografías", denominación que Donna Williams (2012, p. 14) confiere a los testimonios de autistas, debido, entre otras razones, a la importancia que adquiere en sus experiencias subjetivas el acceso a esta nominación que, en la actualidad, se admite con orgullo, como una auténtica identidad frente a los llamados "neurotípicos" o "alistas".

Schovanec teje el relato entre sus recuerdos y la autoobservación contrastada acerca de sus peculiaridades y de las reacciones que éstas despiertan en los demás. Si en una primera toma de contacto puede ser considerado idiota, en un segundo momento, cuando, aún reconociendo su autismo, menciona sus estudios de ciencias políticas, su doctorado en filosofía y su condición de políglota, la valoración vira hacia la genialidad.

"Escribir es más fácil que hablar" afirma; gracias a la lectura y a la escritura pudo progresar en los aprendizajes destacando por sus buenas notas. Una pasión por el conocimiento que admite, fue el resultado de un "encuentro": su padre le regaló un pequeño libro de astronomía, que aprendió de memoria. Más tarde un colega de su padre le obsequió un número de la revista Ciel et Espace, consolidándose así la astronomía como "algo más que una pasión", se convirtió en un "auténtico instrumento creativo de su personalidad" y de su "socialización virtual” porque una revista para apasionados habla de personas concretas, que se comunican a fin de prever encuentros y reuniones, seminarios; también se publican reseñas, etc ${ }^{1}$.

La avidez de Schovanec por el conocimiento, calificada por él mismo como "su toxicomanía" se evidenció desde pequeño, cuando, visitante asiduo de las bibliotecas, devoraba libros de diez en diez de cada estantería. Su extraño comportamiento despertaba incomprensión y hostilidad en sus compañeros y profesores, estaba solo, tenía miedo, recibía golpes a diario, era "incapaz de los discursos sociales, esos que crean lazos y, más fundamentalmente, hacen que a su autor se le considere humano y cuerdo" (Schovanec, 2015, p. 26). Reconoce que le causaba “...más violencia verbal una invitación a desayunar a casa de unos amigos de sus padres que el hecho de ser insultado..." (Schovanec, 2015, p. 82).

También describe sus dificultades con su cuerpo, no le resultó fácil aprender a andar, y por este motivo y a pesar de su esfuerzo por estar con los otros niños, de pequeño no podía participar en juegos de grupo. Tenía arrebatos de ira y momentos de repliegue completo a causa de la ansiedad, pudiendo pasar horas escondido, algo que 
considera muy positivo, un derecho que debería respetarse, al aislamiento con ánimo de protección, con el fin de encontrar "calma sensorial". Más tarde, reconociendo sus rarezas, hurgó en los tratados de psiquiatría, psicología y psicoanálisis buscando una explicación a su insólito comportamiento. "Gracias a Internet, gracias a multitud de indicios, de repente contaba con unas cuantas pruebas de que estaba loco de atar" (Schovanec, 2015, p. 82).

Frente a la dificultad de definir el autismo, se inclina por asociarlo a la locura y no a la discapacidad, entendiendo que ésta conlleva la noción de déficit con su corolario de mediciones y su correspondiente séquito de arbitrariedades. Schovanec plantea los interrogantes fundamentales para avanzar en una dirección no "capacitista" y lo ilustra de buen grado con su propia historia ${ }^{2}$. No recuerda el momento en que empezó a hablar, pero lo cierto es que hasta los seis o siete años sólo su familia podía comprender lo que decía ${ }^{3}$.

Por ello, afirma con justeza, "antes de exigir cualquier cosa a un niño, hay que ponerse de acuerdo en lo que quiere decir "hablar" (...): "un niño que sabe leer cartas medievales en latín y comentarlas por escrito, es un retrasado mental?" (Schovanec, 2015, p. 24). Y abunda en este razonamiento: "Supongamos que usted es psicólogo. Le traen un niño autista a la consulta que empieza a hablar diciendo estas palabras: "Alnitak, Alnilam, Mintaka". ¿Deduciría que le afecta alguna forma de psicosis infantil? ¿Autismo limitante de toda comunicación humana? ¿O en cambio usted reconocería los nombres de tres estrellas del cinturón de Orión y comenzaría una jugosa conversación sobre astronomía?” (Schovanec, 2015, p. 25).

Schovanec no duda en establecer con "ánimo burlón” la vinculación del autismo a la locura; admitiendo que el libro La nave de los necios (en algunas traducciones figura "locos") le ha influido mucho, así como la obra de Foucault y por supuesto, el psicoanálisis, declarando su admiración por las Memorias de D. P. Schreber", texto que califica de "admirablemente escrito, muy razonado", y que un escritor actual habría transformado, con algunos pocos cambios, en una obra de "apariencia sana, no alienada". Y, entonces, se pregunta ¿por qué la locura de algunos personajes conocidos como la de Nietzsche, no se corresponde con los cánones médicos? Una cuestión que enlaza con la médula de la indagación que Michel Foucault (1961/1967) enhebra en su Historia de la locura y que debería formar parte de la formación elemental de las carreras universitarias del campo psi. Tal era la valoración de Lacan sobre esta obra a la que califica de "libro absolutamente capital" porque permite esclarecer la mutación esencial que hizo posible tanto el surgimiento de la ciencia como el aislamiento de la locura. Este hecho, el encierro, determina la idea misma de síntoma, un aspecto fundamental para la clínica.

Foucault sitúa en el paisaje imaginario del Renacimiento la emergencia de las figuras que se convertirán, a través del transcurso de dos siglos, en la "verdadera herencia de la lepra" como encarnación de "los miedos seculares" cuando, debido a los "afanes de separación, de exclusión, de purificación" se consolide el fenómeno de la locura hasta precipitarse su segregación con el confinamiento en las casas correccionales 
y en los hospitales psiquiátricos. Hasta el siglo XV los locos vivían una existencia errante; entre la amenaza y el ridículo, encarnaban la sinrazón, estigmatizando los vicios y los defectos.

La aparición, en 1492, de Narrenshiff, La nave de los locos de Brant y del Elogio de la locura de Erasmo en 1509 ilustra un giro en la historia de la civilización; ambos constituyen exponentes del cambio de paradigma que tuvo lugar en el tránsito de la Edad Media a la Edad Moderna ${ }^{6}$.

El primero presenta la locura asociada a los "extraños caminos del saber" , reúne una serie de retratos elaborados a partir de los efectos que la desmesura ocasiona en los seres humanos, por naturaleza proclives al mal -desde el perezoso al blasfemo- $y$ a la ignorancia, entre los que destaca el fatuo, cautivo del amor propio: "pues lo que a todo necio le ocurre es que quiere ser lo que no es" 8 . Es precisamente en torno al tipo particular de dificultad de articulación entre el ser y el saber donde va a dirimirse la especificidad del autismo en los estudios propiciados por la enseñanza de Lacan.

Erasmo, por su parte, "reserva en su ronda de locos un amplio espacio a los hombres del saber"9 afirma Foucault, y ello no se debe a que la locura conserve sus secretos, sino por ser el castigo de una ciencia inútil y desordenada; en lugar de remitirse al Libro de la experiencia, la ciencia cae en la locura debido al exceso propio de "las falsas ciencias", en forma de punición cómica a su presunción, en tanto la locura "constituye una relación sutil que el hombre mantiene consigo mismo". Y añade: "Filautía", el apego a sí mismo, es su primera señal ${ }^{10}$.

En fin, en palabras de Schovanec, el mérito de esos libros radica en que no hay en ellos una definición clara de la locura, ambos abarcan una diversidad de seres, incluidos por supuesto los propios autores; la locura "es una forma de ver el mundo". De ahí que se pueda contemplar como una desgracia el "progreso" de las clasificaciones, teniendo en cuenta todo lo valioso que han dejado en el camino; ser normal es bien triste, declara, no sin manifestar su preferencia por la compañía de locos.

\section{El tratamiento del autismo en la orientación lacaniana del psicoanálisis}

Foucault sitúa en el Renacimiento la raíz de un aspecto decisivo a fin de llevar a cabo un análisis crítico de la situación que Schovanec lamenta al referirse al estado actual de los discursos sobre la discapacidad y su plasmación en estadísticas y protocolos de evaluación. Se trata de la oposición de la experiencia "cósmica" de la locura, en la proximidad de sus formas fascinantes y una experiencia "crítica" de esta misma locura, en la distancia que facilita la ironía. Esa distancia irá aumentando, afirma, hasta dar lugar a dos formas de experiencia de la locura: en una se aísla su aspecto trágico, en la otra, el elemento crítico, abriendo una brecha que irá aumentando sin cesar con el curso del tiempo. "Por un lado, una Nave de los locos, cargada de rostros gesticulantes, que se hunde poco a poco en la noche del mundo, entre paisajes que hablan de la extraña alquimia de los conocimientos, de las sordas amenazas de 
la bestialidad, y del fin de los tiempos. Por otro lado, habrá una Nave de los locos que forme para los sabios la Odisea ejemplar y didáctica de los defectos humanos" (Foucault, 1961/1967, pp. 48-49).

Así, la locura se convertirá en el objeto de la mirada del sabio y, al tiempo que esta conciencia crítica obtenía más relieve, sus figuras trágicas entrarían progresivamente en la sombra. Foucault encuentra que en la obra de Shakespeare y Cervantes aún se puede reconocer su vestigio, aunque portan la marca de un desgarramiento irremediable que precede a la muerte: en el dramaturgo inglés las locuras se presentan emparentadas con la muerte y el homicidio; en el escritor español adoptan las formas de "la presunción y las complacencias de lo imaginario". Sin embargo, al referirse a las figuras trágicas de la locura en Shakespeare, Foucault menciona a Macbeth y Ofelia, no a Hamlet, cuyo enigma permaneció incólume hasta que Lacan le dedicara gran parte de su seminario VI, El deseo y su interpretación.

Bajo las formas filosóficas o científicas derivadas del cogito cartesiano, apoyo del pensamiento como "ejercicio de soberanía del sujeto" se fue espesando el velo sobre la dimensión trágica de la locura que volvería a palpitar en autores como Nietzsche y Freud afirma Foucault. Pero el "acontecimiento Freud" no puede incluirse en una mera sucesión de autores, marca una ruptura, da lugar a un discurso nuevo sobre los padecimientos subjetivos vinculados al descubrimiento del inconsciente; sus avances fueron poco a poco reduciendo la brecha localizada por Foucault, al enlazar la elaboración conceptual y crítica de la locura con la realidad de la clínica al rescatar su dimensión "trágica" en una práctica novedosa de la palabra (Coccoz, 2021).

En su tesis doctoral dedicada a la paranoia, Jacques Lacan llevó a cabo un ordenamiento del saber psiquiátrico elaborado hasta entonces; allí anticipaba que el psicoanálisis permitiría la elaboración de una "nueva antropología" gracias a la cual sería posible acceder a una verdadera articulación de los puentes necesarios entre ambas "naves". Los enigmas del autocastigo habían orientado su navegación hacia el saber freudiano y la distinción precisa de las estructuras clínicas que éste posibilita con el propósito de hallar las claves de un tratamiento posible. Lacan "no retrocedió ante la psicosis", y ello no como suele creerse, por intrepidez terapéutica sino en función de su rigor doctrinal, en estricta dependencia de los hechos clínicos.

Acerca de la causalidad psíquica (Lacan, 2006) presenta una toma de posición tajante frente al "organodinamismo" de Henry Ey, cuya teoría biologicista propendía a destacar el carácter deficitario de las psicosis. Su argumentación, destinada a demostrar la tesis sobre la causalidad psíquica que las diferenciaba de las demencias se anuda a la consideración de un "margen de libertad" que vinculaba la experiencia singular a "una insondable decisión del ser".

A medida que progresaba en su enseñanza Lacan fue elaborando una noción operativa de las pulsiones de vida y muerte, considerada por muchos autores, también por Foucault, como una mera descripción del elemento trágico en la figura del alienado. Este recorrido le llevó a sustituir la noción de sujeto por la de ser hablante (parlêtre), uniendo en un solo término el saber (lo simbólico, la palabra) y 
el ser, elaborando una clínica del síntoma que trasciende las estructuras al atender a la solución singular que elabora cada uno para sostenerse en la existencia. Así, un día Lacan llegó a proferir: Todo el mundo es loco, un enunciado que Jacques-Alain Miller eligió como título para su curso del año 2007-2008. Nos explica su alcance de este modo: "todo el mundo es loco, es decir, delirante" (Miller, 2015, p. 342) cuando predica universales, cuando proclama una verdad válida para todos. El discurso analítico $^{11}$ es el único que admite la imposibilidad de enunciar dicha ley, la clínica se rige por el principio de uno por uno, nos enseña a reconocer "esta locura genérica, la de cada uno encerrado en su mundo y la imposibilidad de un mundo común" dice Miller.

El año anterior Miller ya había señalado que el autismo "es el estado nativo del sujeto" porque, decía, "se habla solo, se vuelve a decir siempre la misma cosa" (Miller, 2013, p. 119). Entonces ¿el discurso analítico propone una sola nave? ¿La Nave de los locos, la Nave de los autistas?

Es precisamente lo que requiere un esclarecimiento. Porque existe un saber sobre el autismo, que se ha ido elaborando a partir de décadas de práctica analítica y del testimonio de los propios sujetos concernidos; pero existe lo real de la neurosis, lo real de la psicosis, y existe lo real del autismo que se distinguen en cuanto distintas posiciones subjetivas en la existencia, como respuestas ante lo real, es decir, a la complejidad propia de nuestra condición de seres hablantes, náufragos en el mar del lenguaje, sin la garantía de una brújula innata para encontrar el norte.

$\mathrm{Si}$ admitimos con Lacan que en los autistas "la palabra se congela" debemos estar atentos a los modos posibles del "descongelamiento" que singulariza el estilo de cada sujeto (Langelez Stevens, 2021). En muchos casos ha sido el producto de un "autotratamiento" eficaz (Donna Williams, Josef Schovanec, Daniel Tamet, Temple Grandin) pero, en muchos otros, se manifiesta en su dimensión trágica, de angustia, de agitación máxima, en formas extremas de la defensa del mutismo y aislamiento y que requieren, por lo tanto, de una intervención adecuada, orientada, precisa, para facilitar el acceso al lazo social.

Por tal motivo podemos calibrar la importancia histórica que adquirió la presentación en el Seminario de Lacan, y por parte de su alumna Rosine Lefort, del caso Robert en el año 1955, inaugurándose en ese acto una modalidad de acogida del sufrimiento infantil -su elemento trágico- desde una perspectiva crítica- el saber sobre la formación del ser como ser de palabra. Retomando la interrogación de Schovanec, ¿qué quiere decir hablar cuando un niño de cuatro años emite un solo enunciado? “El lobo El lobo!” aullaba aterrado; en otro momento él aterrorizaba a los demás; ése era pues el nombre de su dolor y a la vez, el de su ser, identificado a esa imagen horrible. Lacan valora ese elemento aislado como el "germen de la palabra" (Lacan, 1981, p. 164), a partir del cual, si lo acompaña una presencia atenta y advertida como Rosine Lefort, se puede iniciar una serie y con ella, el vínculo que propicia su humanización. Considerar el autismo como una estructura aparte, y a los autistas, aún mudos, como seres de palabra, es el principio ético que rige la acción lacaniana. 


\section{Semblantes y síntomas de la locura}

Lacan califica de locura al hecho inevitable, a la relación con el ser que nos impone el lenguaje, razón por la cual referirse a "seres hablantes" le parece una tautología. Por otra parte, define el inconsciente como "el misterio del cuerpo que habla", el "misterio de la encarnación", la imprevisible forma en que "toman cuerpo" los seres de lenguaje, los semblantes, las máscaras, que habitamos con mayor o menor comodidad. Por tal motivo se muestra categórico, los poetas nos llevan la delantera, al plasmar "los grandes temas míticos" de la existencia respecto a los cuales sus "creaciones se ponen a prueba a través de las épocas". En la sucesión de variaciones que se extiende por siglos y siglos se verifica una larga aproximación en la que sus posibilidades [las del mito] son analizadas con precisión y puedan entrar, en sentido estricto, en la subjetividad y en la psicología, afirma. "Sostengo y sostendré sin ambigüedad -y al hacerlo creo estar en la línea de Freud- que las creaciones poéticas engendran las creaciones psicológicas, más que reflejarlas" (Lacan, 2014, p. 275). Es una advertencia para quien pretenda hacer una nueva psicopatología a partir del psicoanálisis; los "tipos clínicos" fueron inicialmente creaciones literarias, tal como lo intuye Schovanec siguiendo a Foucault.

En tal sentido puede apreciarse hasta qué punto la práctica del psicoanálisis es anti-segregativa; las neurosis, las psicosis y el autismo son consideradas distintas posiciones subjetivas en la existencia, y lo fundamental de la operación se orienta a restituir o crear el lugar del sujeto en el discurso, en el lazo social, a partir de otorgar al síntoma la dignidad de una creación en donde está presente lo más singular y no lo que debe ser eliminado en razón de la norma. Por tal razón, Lacan lleva a cabo una crítica severa a la entronización del yo como garantía de la realidad y sede de la "alianza terapéutica". A través de la lectura hegeliana del narcisismo freudiano, Lacan define al yo como una "función de desconocimiento" mediante la que "el sujeto se piensa, se ve, se cree distinto de lo que es" (Miller, 2011, p. 108).

Su texto Acerca de la causalidad psíquica "solo en apariencia es un texto sobre la psicosis" explica Miller; retoma allí el caso Aimée (Lacan, 1979) para hacer de ella una "fenomenología de la locura (...) la psicosis aparece como una subclase, incluso como un subproducto de la locura -de una locura mucho más fundamental, "coextensiva" de la humanidad" (Miller, 2011, p. 108).

El fenómeno de la locura, continúa Miller, es el desconocimiento intrínseco a todo conocimiento de sí, al punto que no puede separarse del problema de la significación (...), es decir, del lenguaje en el hombre", la sustancia misma de su reflexión. Encuentra en la figura hegeliana de la "ley del corazón", el nódulo del desconocimiento por el cual la conciencia de sí llega a identificarse "de forma inmediata" con la ley universal sin tener en cuenta a los demás corazones quienes, al enterarse, se manifiestan hostiles a la verdad y justicia pretendidas. La respuesta que encuentra en los demás deja aparecer su ser actual, como víctima del "orden público", por vía del contragolpe social y en oposición a su singularidad. El sujeto "participa del desorden ante el que se subleva", así lo ilustran las figuras trágicas de 
Karl Moor de la obra teatral de Schiller Los bandidos y Alcestes en El misántropo de Moliére. "Hay locura cuando el sujeto se identifica a lo universal sin mediación", aunque Lacan supo reconocer que en esa locura de la ley del corazón está presente lo mejor que posee el sujeto, su ideal de libertad, y por ello, añade Miller, considera la locura como "la permanente virtualidad de una grieta abierta en su ser". La locura es compañera de la libertad, la libertad de querer ser otra cosa de lo que se es" (Miller, 2011, p. 112). Si bien es preciso tener en cuenta que "creerse lo que uno es" no es mejor, la expresión "creerse" subraya la infatuación pudiendo alcanzar la forma del delirio de presunción.

Sin pretender agotar la finura de estos desarrollos de Lacan, examinados cuidadosamente y enriquecidos por Miller, retengamos la perspectiva novedosa de la clínica que permitió distinguir el yo -clínicamente "preñado de delirio"- y la dimensión del ser, mediatizada por el Otro, es decir, por la existencia en la palabra en donde el sujeto puede realizarse como deseo, -definido como la falta en ser- que se orienta por la identificación al Ideal del yo, un "polo de atributos" localizado en el discurso del Otro. La locura se define como una identificación sin mediación, una declaración del ser que prescinde del reconocimiento de los demás, que se consuma en un rechazo al Otro.

El estudio de los síntomas específicos de las psicosis en el campo de la palabra y el lenguaje ocupará el Seminario III teniendo como guía el texto de Schreber hasta cernir la causa precisa en el orden simbólico -la forclusión- de cuyos efectos catastróficos el sujeto testimonia en sus Memorias. Se inaugura entonces la vía del "tratamiento posible" por medio de las suplencias de esa carencia estructural, una brújula muy atinada con la cual el psicoanálisis encontró otra manera de intervención, diferente del procedimiento interpretativo freudiano.

\section{Hamlet o el "enloquecimiento del deseo"}

Lacan acometió su enseñanza llevando a cabo una traducción de la obra de Freud que, en una primera época, tomó apoyo en los desarrollos de la lingüística y en la teoría del reconocimiento sustentada en la filosofía de Hegel hasta llegar a construir el grafo del deseo en el que presenta una novedosa topología del inconsciente. Lo pondrá a prueba al deletrear el enigma de Hamlet, la elección dramática de su existencia que se formula como To be or not to be. Propone la tesis cuya demostración despliega a través de siete clases de su seminario: “...la obra pone en juego diferentes planos, el marco (...) donde va a situarse el deseo. El lugar del deseo se articula de un modo tan excelente y excepcional que todo el mundo llega a reconocerse en él" (Lacan, 2014, p. 286).

Ahora bien, Lacan insiste, Hamlet no es un caso, "no es un personaje real" sino dramático, de hecho, las múltiples interpretaciones que se han sucedido a lo largo de los años son "inconciliables, contradictorias" y, al revés de lo que podría creerse, desde el discurso analítico, no tenemos que vérnoslas con el inconsciente del poeta, 
nuestro interés principal no se dirige allí, añade. La obra vale por su organización, por los planos superpuestos que instaura, en cuyo interior puede hallar cabida la dimensión propia de la subjetividad humana, y ello en la medida en que "inaugura una nueva dimensión del hombre”.

Si la filosofía se ha mantenido en "soy en la medida en que pienso que soy", no hay razones para que esto se detenga, afirma Lacan, tachándolo de delirio, fecundo, aclara, pero delirio al fin. Pero el psicoanálisis enseña algo distinto: "que no soy aquel que está pensando que soy, por la simple razón de que, debido a que pienso que soy, pienso en el lugar del Otro. De ello resulta que soy diferente a aquel que piensa Yo soy. Pero no tengo la menor garantía de que el Otro pueda devolverme su ser y su esencia de verdad (...) que pueda responder por lo que soy" (Lacan, 2014, p. 332).

El grafo permite ubicar tal colusión entre el yo -que se piensa ser- y el inconsciente en planos diferentes; en la medida en que el dilema del ser surge en el marco de la tragedia del deseo, suspendido el deseo del Otro, es posible desentrañar "el enloquecimiento del deseo de Hamlet" y la imposibilidad de llevar a cabo el acto que pretende acometer. "El personaje y el drama de Hamlet entran en resonancia metafísica con la cuestión del héroe moderno" (Lacan, 2014, p. 351) cuyo eco puede hallarse en las distintas paradojas que presenta el deseo en la clínica de la histeria y la neurosis obsesiva. Hamlet llegará incluso a "hacerse el loco" dando "forma a la política del héroe moderno"12, él sabe que es el más débil, que se encuentra en una posición peligrosa y de ese modo pude proseguir hasta el momento final, cuando, muerta Ofelia y marcado él mismo por la muerte, pueda, por fin proclamar, "Soy Hamlet, el danés".

\section{El enigma de Bartleby ${ }^{13}$}

Preferiría no hacerlo es la frase proferida por el protagonista del relato Bartleby, el escribiente escrito por Melville en 1856 que se convierte en un emblema, en una rúbrica de un comportamiento desconcertante pero que, aún así, nuestra imaginación acepta inmediatamente, como bien observa Borges. ¿Qué peculiar lección de humanidad podemos extraer de estas pocas y sustanciosas páginas? ¿Qué resortes de la estructura activa el autor en este caso, desbrozando el camino al psicoanalista? ${ }^{14}$

Escrita en primera persona, la narración toma la forma de un testimonio, de una experiencia extraordinaria que tuvo lugar en el transcurso del recorrido profesional y vital de un abogado de Wall Street: su encuentro con el copista Bartleby. Luego de razonar sobre la imposibilidad de escribir una biografía sobre él dado que de su historia nada cierto podía saberse, describe el cuadro en el que hará su aparición. En primer lugar, se presenta a sí mismo como alguien de fuerte personalidad, asentada en tajantes certidumbres "...cuantos me conocen me consideran un hombre eminentemente seguro” (Melville, 1987, p. 233). Luego perfila los tumultuosos caracteres de los copistas que desde tiempo atrás trabajan en su despacho, Turkey y Nippers, y apunta la viveza característica del muchacho que se ocupa de los mandados, Ginger Nut. 
Después explica las circunstancias que le empujaron a buscar otro empleado, decidiéndose por un joven cuya figura describe, admirado: “ipálidamente pulcra, lamentablemente decente, incurablemente desolada!” (Melville, 1987, p. 241). Ese semblante de fragilidad y desamparo le llevó a anticipar la buena influencia que ejercería, en el ambiente de su oficina, un hombre de tan "morigerada apariencia". Tan felices se las prometía el abogado que decidió colocar el escritorio del hombre tranquilo en la zona que él ocupaba, separado por unas vidrieras de los otros empleados: "Para que el arreglo fuera satisfactorio, conseguí un alto biombo verde que enteramente aislara a Bartleby de mi vista, dejándolo, sin embargo, al alcance de mi voz. Así, en cierto modo, se aunaban sociedad y retiro" (Melville, 1987, p. 241). Este emplazamiento ideado por el abogado indica una sutil intuición de las dificultades que debían solventarse. Aislado, protegido del ambiente dicharachero, Bartleby trabajaba día y noche, copiaba "como si hubiera padecido un ayuno de algo que copiar", tan imperiosa como mecánicamente, sin alegría ninguna.

En este contexto tendrá lugar el enfrentamiento entre el abogado y el escribiente, efecto de la discordia entre dos posiciones subjetivas que tomará una forma dramática a lo largo del relato. El trabajo de copista requería la verificación "palabra por palabra" del texto, en el que intervenían dos o más personas, dependiendo de la cantidad de copias. Urgido por la necesidad de un examen semejante, el abogado llamó súbitamente a Bartleby. Convocado a responder a la demanda de participar en lo social, en una tarea compartida con otros, el amanuense replicó “...con voz singularmente suave y firme: Preferiría no hacerlo” (Melville, 1987, p. 242).

\section{Algunas interpretaciones}

En el año 2000 se publicó una nueva traducción española de Bartleby, el escribiente, acompañada por tres interpretaciones acerca de un personaje que, al igual que Hamlet, ha hecho correr ríos de tinta. El primero fue escrito por Gilles Deleuze. Este autor niega que el personaje sea "metáfora del escritor, ni símbolo de nada. Se trata, dice, de un texto de violenta comicidad, y lo cómico es siempre literal” (Deleuze et al., 2000, p. 59). Deleuze afirma que esta expresión surge como un límite del lenguaje, convocando el estupor, enloqueciendo a sus semejantes, y que su fuerza devastadora radica en plantear una imposibilidad, la fórmula elimina lo preferible como cualquier preferencia en particular, gestándose así una zona indiscernible en la que toda particularidad y referencia son abolidas. No es una voluntad de algo sino la emergencia de la nada de voluntad. La fórmula preferiría no hacerlo, desvelaría, según Deleuze, una inspiración "psicótica" que habría prosperado en la literatura americana, descomponiendo la "neurosis" de lengua inglesa a fuerza de distorsionar su sintaxis con el ánimo de inventar una nueva universalidad. Con Bartleby se habría gestado una nueva lógica, la de las preferencias, minando de esta manera los presupuestos del lenguaje. La tensión entre el abogado (que espera que el copista sea su hombre de confianza) y el escribiente que rehúsa, sería la ocasión de percibir la traición al pacto ocasionada por el primero y el nacimiento de un orden nuevo propiciado por 
el hombre anonadado y mecanizado en las grandes metrópolis. Según la lectura deleuziana la fórmula lingüística I prefer not to, revelaría la jerarquía revocada del abogado, como indicio de la destrucción de la función paterna porque priva al padre de su palabra ejemplar, y al hijo de su posibilidad de reproducirla o copiarla.

El proceso es "psicótico" porque no sigue las "aventuras de la neurosis" propias del viejo mundo: aporta un rasgo expresivo informal, no hay sujeto que triunfe o fracase; persigue un sueño, el de establecer la función universal de la fraternidad independiente del padre. El personaje del abogado indica una alternativa: él ha elegido en contra de Bartleby y encarna el intérprete, que hace del otro personaje un ser excluido de la razón. Bartleby es una figura original, un personaje sin racionalidad, que escapa al conocimiento y desafía la psicología. Por ello Deleuze la dota de un carácter profético, por ser la figura que puede reconciliar con la humanidad secundaria, derivada de la destrucción de la función paterna, devoradora y destructora de los hijos. “¿qué pide Bartleby sino confianza mientras que el abogado le ofrece caridad y filantropía, todas las máscaras de la función paterna?" (Deleuze et al., 2000, p. 89). Concluye Deleuze con una exaltación del personaje de Bartleby: no es un enfermo sino el médico de una América enferma, "un nuevo Cristo o hermano de todos nosotros" (Deleuze et al., 2000, p. 92).

Giorgio Agamben, por su parte, encuentra en el personaje de Bartleby, en tanto escribiente, una raigambre filosófica de gran calado. Aristóteles y los textos religiosos y cabalísticos son evocados para ubicarlo en la filiación que concibe la creación como un acto de escritura. Según Agamben el escriba que se niega a escribir del cual Bartleby es la figura más extrema ilustra la potencia perfecta, la cual no puede distinguirse de un acto de creación.

Lo característico de la demostración de Agamben reside en la argumentación de la contingencia en el pasaje de lo posible a lo real; si Bartleby ha dejado de escribir, demuestra una reivindicación de la nada como potencia pura y absoluta. El tema de la potencia en nuestra tradición ética ha sido soslayado con el tema de la voluntad y el de la necesidad: se ha tematizado lo que se quiere o lo que se debe, pero no lo que se puede.

A Agamben le interesa ese aspecto y para explicarse retoma la teología medieval que proponía a Dios como potencia absoluta (puede hacer algo, incluso el mal, según algunos) y la distinguía de Dios como potencia ordenada (sólo puede hacer algo que concuerde con su voluntad). La voluntad es el principio que pone orden en el caos indiferenciado de la potencia. Desde este punto de vista Bartleby cuestionaría la supremacía de la voluntad sobre la potencia. Si Dios puede sólo lo que quiere, Bartleby puede sin querer, manifiesta una potencia absoluta. No por ello su potencia está mermada, ha llegado a poder y a no poder sin quererlo en absoluto, de ahí la irreductibilidad de la fórmula, según Agamben. El personaje del copista destruye la relación entre querer y poder. Su negación no responde a ningún pathos heroico, se aproxima más bien a la fórmula escéptica "esto no es más que aquello". Se trataría de una suspensión, sin predicado alguno. El escribiente se inscribiría en la estirpe de los mensajeros, por ello el abogado llega a vincular su aparición a un designio 
misterioso que los mortales no alcanzan a descifrar. Agamben afirma que la prueba de Bartleby es la de reflejar una imponente posibilidad que sobrepasa el ser y la nada, una potencia purificada de la razón, desprendida de las ataduras de la verdad, figura del nihilismo que anticipa a Nietzsche dando lugar a una mutación antropológica.

Por su parte, el traductor de la obra, José Luis Pardo toma en cuenta en su comentario los presupuestos de Walter Benjamin según los cuales la literatura es una consecuencia de la invención de la privacidad. El misterio que reviste al personaje radica en que no tiene historia, no hay contrastes entre su interioridad y la exterioridad, no es posible hacer de él una biografía, asegura que Bartleby es una pérdida irremediable para la literatura. "Melville prefiere no escribir una novela cuyo narrador prefiere no hacer literatura acerca de un escribiente que prefiere no escribir" (Deleuze et al., 2000, p. 157).

Según Pardo lo que caracteriza las respuestas de Bartleby es que no son negativas sino declinaciones, no son protestas contestatarias sino dilaciones, el amanuense aparece en una dimensión de ontología negativa. El enunciado produce una infracción prágmática porque la frase es incompatible con la situación en que se la utiliza. La orden de un jefe no puede responderse en términos de preferir o no preferir... haciéndolo Bartleby estaría demostrando una efectiva denegación de la sumisión, una resistencia a la obediencia. Bartleby escapa a las interpretaciones en beneficio de la literalidad. Según la hermenéutica, su mensaje escaparía a todo contexto y por ello sus frases son incoherentes desde el punto de vista pragmático, inadecuadas a la situación. Se resiste a ofrecer argumentos que puedan alterar la literalidad de su frágil existencia, los que permitirían encontrar intenciones en el pasado o en el futuro. Es una letra que parece no tener contexto ni circunstancia alguna, excede a toda interpretación ficcional. ¿Habrá que declararle no-humano porque su vida no puede contarse como una historia? Pardo parece inclinarse por una interpretación en sentido opuesto, encuentra en Bartleby "un sentido literal, la huella de una singularidad indómita, no "biografiable", irreductible a la información e incompatible con la argumentación” (Deleuze et al., 2000, p. 187). Bartleby sería el emblema de la literatura negativa, pero factible de ser concebida en términos no negativos (privada de atributos o de personalidad) sino positivos, como liberación de todo contexto (inocencia).

\section{¿Qué aporta el discurso analítico?}

Teniendo en cuenta que al igual que Alcestes, Karl Moor y Hamlet, Bartleby no es un personaje real, no es un caso clínico, pero, en tanto creación literaria, consigue dar forma a aspectos de la existencia en una figuración mítica ${ }^{15}$ que luego se llegan a plasmar en la subjetividad o en la psicología, podemos calibrar la importancia de la lógica que está en juego en la organización del relato hasta su fatal desenlace.

En la tensión entre Bartleby y el abogado el escritor explora y desgrana las distintas reacciones que se suscitan cuando reina el discurso del amo y se pretende conducir, 
dominar, seducir, curar, enseñar, a alguien en franca disidencia con su principio: el amo quiere que las cosas marchen bien, decía Lacan.

Si el relato de Melville es único, es debido a que en él no se ocultan las ambivalencias, las dudas, las fantasías, las tentaciones y actuaciones por parte de quien tiene que vérselas con alguien que, debido a una "insondable decisión del ser", prefiere no hablar, no responder según sus reglas. Y el conflicto se muestra tanto más agudo cuanto que al principio hubo cierto entendimiento; la percepción de la subjetividad desvalida de Bartleby propició su adopción inmediata y la concesión de una disposición adecuada de la oficina para facilitar su estancia: detrás de un biombo, próximo a los otros, pero fuera del alcance de sus miradas, procurándole de este modo "retiro y sociedad".

Pero la inclusión a mínima del amanuense en una realidad discursiva se malogra al intentar forzarle a una actividad colectiva, la de revisar las copias. En ese momento el frágil lazo se rompe y ya no habrá vuelta atrás. Es asombrosa la sutileza con la que el artista construye una situación sin escapatoria, la impotencia con la que se estrellan las buenas intenciones, y en donde arraigan sus posibles violencias, porque se desconoce la lógica en la que el sujeto está atrapado. No hay salida para los que prefieren no hacer ni decir lo que se ha estipulado, lo que se espera, se impone o se demanda. Las interpretaciones de las conductas en términos de poder o impotencia, para ensalzarlas o condenarlas, dejan de lado que es posible otro tratamiento de los signos del sujeto que rechaza el diálogo y, huyendo de la colaboración, se niega a la participación.

El discurso analítico ofrece otro tratamiento a las formas radicales del No, indagando en los posibles Sí. Al evitar la oposición frontal con lo imposible -lo realde una subjetividad que no ha conseguido habitar la palabra con placer y soltura, se promueve otra manera de hablar, se respeta el silencio. Y ello en la medida en que, en el discurso psicoanalítico, los síntomas no se consideran déficits sino signos de la subjetividad, entendida ésta como una posición existencial, fruto de un trabajo de defensa ingente frente a la angustia, que debemos entender inconmensurable si sabemos escucharlos ${ }^{16}$. El tratamiento se orienta por la brújula ética que concede a los autistas su dignidad de seres de palabra, aún a los confinados en un mutismo absoluto, Lacan consideraba a los autistas "más bien verbosos".

¿De qué manera hablar a aquéllos cuya defensa es extrema, radical? ¿Cómo dialogar con quienes prefieren no hacerlo por carecer de una pantalla psíquica y protectora frente a la invasión de estímulos que les obliga incluso a taparse los oídos y a rehuir del contacto? ¿Cómo atenuar los efectos desastrosos que se expresan como agitación, violencia, mutismo? ¿Cómo dirigirse a aquéllos que no responden a la demanda o cuyas demandas son imperiosas, exigentes, perentorias? ¿cómo maniobrar para evitar penosas consecuencias?

Hemos de partir de la dificultad estructural de los autistas, en la ausencia de la función del Otro, en la deslocalización (Zenoni, 2009) de la función simbólica del destinatario donde debe articularse un lugar de enunciación propio, eso si tenemos en cuenta que, en el marco de la comunicación humana "no se trata sólo de hablar, 
sino de hablarle a alguien" (Lacan, 1994, p. 344), advertía Lacan y en torno a este hecho, tan inmenso como habitual y sin garantías, gira nuestra existencia.

\section{La formación de la tecnotribu autista}

¿Cuáles son los cambios inducidos por la revolución tecnológica en la realidad de los seres hablantes, en sus existencias, sus deseos, su relación con el lenguaje y los otros? Esta cuestión atraviesa el libro de Javier Echeverría titulado Tecnopersonas (Echeverría y Almendros, 2020), en el que inaugura un campo semántico a partir del uso del prefijo "tecno" desde la premisa de que los tecnolenguajes del siglo XXI generan tecnopersonas. Echeverría se remite al origen del término persona, del etrusco phersu, que significaba "enmascarado", una precisión que considera muy útil a fin de analizar "las actuales máscaras digitales" con las que se presentan los usuarios de Internet y de las redes sociales. Recoge también el término prosopon con el que se traducía al griego clásico persona: "lo que se presenta de sí a la mirada del otro", algo así como un sello de nuestra identidad. Con razón apunta Echeverría a que el maquillaje y los vestidos forman parte desde siempre de la vida comunitaria, y es en esa función de esa imagen, constitutiva del ser en la representación, donde pueden situarse ciertas formaciones gregarias que hicieron su aparición en la segunda mitad del siglo XX y recibieron el nombre de "tribus urbanas" ${ }^{17}$.

Propongo nombrar "tecnotribu" a la red de intercambio y comunicación que han formado los autistas, un hecho favorecido por su carácter "indirecto", no presencial, favorable por lo tanto a la peculiaridad de la defensa, a partir de constituir una topología del espacio subjetivo que no compromete directamente el cuerpo y sus requerimientos en el intercambio con los demás. En esta perspectiva tengo en cuenta los aportes doctrinales de Eric Laurent y Jean-Claude Maleval y la clínica del autismo llevada a cabo en las instituciones de orientación lacaniana (Coccoz, 2013, 2017), así como el estudio de los testimonios de autistas. En el curso de las últimas décadas estas aportaciones han dado lugar a la constitución de un saber muy contrastado que hizo posible cernir de forma más precisa la estructura.

Así como hemos tenido ocasión de conocer, gracias a la invención de la "comunicación asistida" el recorrido particular de autistas considerados "severos" como Birger Sellin y Hélène Babouillec, es posible valorar, a partir de los tweets, las publicaciones en Instagram, los vídeos en youtube, la importancia que adquiere para los autistas declarar públicamente su diagnóstico, en la medida en que les provee de un sentimiento de identidad que juzgan como una valiosa conquista ${ }^{18}$.

En su texto Hielo y deshielo del S1 en el sujeto autista, Jean-Claude Maleval y Michel Grollier (2021) exploran la peculiaridad dela cuestión de la identidad en la subjetividad autista que indagan teniendo en cuenta que la permanencia del sentimiento de identidad se comprueba independientemente de los cambios que puedan afectar al cuerpo y de la diversidad de roles que puedan asumirse (así lo demuestran los actores y las actrices). Desde la perspectiva de Freud ${ }^{19}$, el corazón de la identidad reside en 
la identificación, en la constancia que adquiere un elemento significante destacado en el Otro que Lacan nombró "significante unario" porque tiene una función de unificador, al representar el sujeto respecto de los demás significantes y cuya función se detecta en la enunciación personal, en un decir propio.

A partir de un estudio pormenorizado de los testimonios y de casos clínicos, estos autores aportan precisiones fundamentales: en primer lugar, que el autista testimonia inicialmente una identidad "borrosa", la identificación primordial no es estable, el sujeto resiente su inconstancia y las identificaciones yoicas son vividas como falsas. Tan cierto como que muchas veces llegan a conquistar un asiento identitario, y que resulta de un largo trabajo subjetivo en el que pueden distinguirse unas etapas que llegan a precisar. Se constata que en las formas iniciales del autismo el sujeto no se reconoce en el espejo, no responde a su nombre, no utiliza casi el pronombre Yo (Je). En algunos la vida se apaga, no invisten su cuerpo, y resienten el vacío interior; en algunos se presenta un acusado negativismo, y en casos extremos, aún si sufren crisis de pánico se aferran a la inmutabilidad. En cambio, otros, como Birger Sellin, no experimentan ninguna confusión de identidad, a pesar de su "dependencia fusional" respecto de su madre, su obra testimonia de una "independencia pensada o intelectual" (Sellin, 2011).

En segundo lugar, estudian la identidad "transitivista", distinguida, siguiendo a Lacan, a partir de la captura que puede llegar a ejercer la imagen del otro y que permite pasar de una identidad borrosa a tomar apoyo en un doble, a través del mimetismo y de "juegos de espejo", que les proporciona un dinamismo, aportándoles el sentimiento de estar vivos, y cumplen a la vez con la defensa mayor destinada a evitar las emociones, imponiéndoles una ardua lucha entre el intelecto y los afectos. Un ejemplo de este tipo de identidad nos la ofrece J. Schovanec, al referir que vez terminado los estudios secundarios, todo hacía pensar que se dedicaría a las Matemáticas, (“yo quería ser matemático"); sin embargo, su hermana le matriculó en Ciencias Políticas, hecho que fue asumido sin rechistar, como una evidencia (Schovanec, 2015, p. 51).

En tercer lugar, distinguen la identidad "disimulada", no sin advertir que la diferencia con la transitivista no es tajante, pudiendo verificarse formas de pasaje entre una y otra. La identidad disimulada compensa el vacío con un modelo, que funciona como una fachada detrás de la cual conservan la consciencia de la impostura; según Donna Williams a través de esos "compañeros imaginarios", "máscaras", "rostros" o "personajes", y ante la ausencia del sentido interno del cuerpo, le fue posible "jugar la comedia" humana. Ella también se refiere a sus "estrategias de abnegación", desplegadas para parecer normal ${ }^{20}$.

También es comentado el caso de Temple Grandin y el misterio de su identificación a la vaca, a partir de la cual encontró alivio a su ansiedad incontrolable. Gracias a "la máquina de apretar" que encontró en el uso de las máquinas de contención para animales pudo volver a conectar el afecto y las imágenes, iniciando un camino que la convertiría en reconocida especialista en ciencias animales años más tarde (Grandin, 2001, p. 169). 
Y el de Hugo Horiot, autor de Carnet d’un imposteur, quien encontró una solución exitosa a la identificación disimulada convirtiéndose en actor profesional, una experiencia que contrasta con la de Donna Williams quien consideraba dicha identificación como una "mutilación psíquica" y cuya experiencia sin igual hasta conseguir el desprendimiento de sus dobles (llevado a cabo con el firme propósito de habitar su cuerpo) describe con todo detalle en su "autibiografía" (Williams, 2012).

En fin, Maleval y Grollier describen un arco en uno de cuyos extremos ubican algunas personas como Hélène Babouillec $(2018)^{21}$, quien aferrada al silencio, renuncia a la fachada y reivindica una identidad tan profunda como inalcanzable, donde encuentra la certeza de un "amor sin fallas" y, en el otro extremo, las formas atenuadas del espectro en las que el sujeto se contenta con dar una cierta consistencia a su vacuidad apoyándose en varios modelos, siendo indiscernible su conducta de un conformismo social, y revelando un costado "camaleónico" que puede aparecer incluso como "un exceso de normalidad".

Ellos han tomado buena nota de la observación de Lacan, de que en el autista "la palabra se congela", así como la importancia de constatar, como lo hiciera él mismo en la presentación del caso Robert a la que aludimos antes, la presencia del sujeto "que está ahí, pero no responde". Se comprueba que un "sí mismo mínimo" puede detectarse en los autistas, incluso en aquellos "cortados de la vida" y ello se verifica en el hecho de que son capaces de mostrarse muy activos cuando se trata de protegerse de aquello que los angustia.

Retenemos una lección a tener en cuenta en la clínica del autismo: “...el evitamiento del otro, el corte respecto a los afectos, resultan de una actividad fuerte y persistente que testimonia de un trabajo subjetivo sostenido" (Maleval y Grollier, 2021, p. 11). Una afirmación que confirma los hallazgos de Antonio Di Ciaccia quien inventó "la práctica entre varios" al conseguir captar la lógica de las conductas repetitivas y las ecolalias en el autismo infantil, pudiendo considerar que, en ellas, "el sujeto está al trabajo" y que la cuestión fundamental es lograr constituirse en su partenaire.

Luego del examen de la identidad borrosa, transitivista y simulada Maleval y Grollier profundizan en las operaciones que han hecho posible el "deshielo" favoreciendo la vivencia de una "identidad asumida" a partir de una mutación subjetiva decisiva que permite la experiencia del cuerpo, -hasta entonces vivido como ajeno-, el cual va siendo poco a poco habitado, a la vez que se renuncia al "recurso alienante del borde" donde se concentraba hasta entonces lo vivo, ocupado por un objeto, un doble o un disfraz (sobre la función del borde en el autismo, véase Laurent, 2012). El examen de la transformación que puede tener lugar respecto de las emociones es luminoso, constatan que el rechazo de los afectos pesa sobre todo sobre el amor y los sentimientos positivos, siendo en general mejor admitidas por el sujeto autista las reacciones de ira, agresividad, al dejar patente el rechazo. Los testimonios de Daniel Tammet, Donna Williams, Jim Sinclair, Temple Grandin entre otros, 
constituyen una enseñanza respecto al "encuentro" que hace posible la relación al otro, facilitando una inserción social y, por lo tanto, una orientación para la clínica, destinada a favorecer la construcción de la identidad autista.

A estos desarrollos sobre la problemática de la identidad autista debemos añadir el análisis llevado a cabo por Juan Pablo Luccheli, cuando demuestra la causa de la denominada "ceguera mental" o "ausencia de empatía" o de "una teoría del espíritu" que parecería justificar la carencia de habilidades sociales con las que se define el espectro. Luccheli retoma el estadio del espejo, formador del yo, cuya consolidación depende del gesto, de la percepción de la mirada del Otro y a falta de la cual no hay acceso a la representación, ni siquiera la del cuerpo propio. "No hay relación directa con el mundo", afirma, para ello hace falta la significación del Otro. Por lo tanto, la relación con el mundo del autista no se produce por esta vía, se trata de una incorporación al mundo diferente (Luccheli, 2020).

$\mathrm{Y}$ en este sentido el mundo virtual se verifica como un facilitador para una multiplicidad de personas que, celebrando la construcción de estos puentes, más precisamente "tecnopuentes" pueden comunicar sus experiencias que van desde la exposición detallada de sus dificultades con el cuerpo y sus funciones, hasta el testimonio de su soledad, de sus fracasos y hallazgos en la relación con el mundo, con los demás y con el saber.

Pero seguramente, más allá del Otro, en principio anónimo al que se dirigen y cuyo lugar incierto se constituye y anima de seguidores, que responden o no a la forma de diálogo en que suelen redactarse los mensajes convocando a los semejantes a una experiencia compartida, más allá, decimos, se perfila el otro mundo del que fueron excluidos, el mundo neurotípico ante cuyos imperativos manifiestan su legítima insurrección. Aunque en la formación de la tecnotribu la experiencia del cuerpo no se produce, tampoco la angustia tiene traducción virtual y las imágenes, los selfies, incluso fotos y vídeos que ilustran sus transformaciones corporales no saturan la búsqueda de un suplemento de identidad que algunos esperan encontrar en ese intercambio y con ello atenuar su dolorosa soledad. Si bien en muchos casos se puede calibrar un afianzamiento personal como resultado de la neo-especularidad que proporciona "el estadio del espejo electrónico" según lo ha tematizado Clotilde Léguil ${ }^{22}$ es preciso contemplar el riesgo de permanencia en un espacio bidimensional cuya incidencia en la vivencia del cuerpo como ajeno ha sido destacado frecuentemente. J. Schovanec explica algunas de las dificultades que esto entraña: por carecer de motricidad fina, le costaba atarse los cordones, tampoco podía jugar al fútbol con los otros niños en el recreo del colegio, al no poder "visualizar la trayectoria del balón en tres dimensiones"23. 
Algunos autistas trabajan muy seriamente en favor de la consolidación de la tribu, llegando incluso a formular un mundo posible de autistas y los modos de reconocimiento entre pares, a la vez que ironizan sobre los rasgos característicos de los NT y difunden advertencias respecto a tratamientos autoritarios. En algunos casos, como Asper Revolution, asumiendo posiciones muy valientes, como leemos en su texto El autismo no existe. "Lo que sí existe, sí existimos somos las personas autistas (...) en una posición política de vulnerabilidad debido a cómo se estructura la sociedad aquí y ahora. Lo que sí existe es la gente autista, gente de todo tipo, con infinidad de personalidades diferenciadas, con sus propias inquietudes, creencias y valores.

Tenemos muchas características en común, especialmente en contraposición a la población NT, pero eso no significa que todes tengamos algo llamado autismo metido dentro (...) Cuando se investiga para terminar con el autismo, significa que se está investigando para que dejen de nacer personas autistas. Porque supongo que es mejor impedir que nazcan cierto tipo de personas que adaptar la sociedad para que sea más amable y adaptada a quienes la habitamos. Lo que se está diciendo de forma tácita es que hay personas que merecen vivir en este mundo y personas que no. Esto va muy ligado a la idea del capitalismo, a ser útiles, productivos, a ganarse la vida, como si ésta fuera un concurso y el premio fuera continuar existiendo un poco más”24.

En este sentido, Josef Schovanech reconoce que "si tuviese que encontrar un trabajo por la vía ordinaria no lo hallaría jamás" (Schovanec, 2015, p. 170) y eso a pesar de la extensión de su currículum... o a causa del mismo, "el ritual" de las entrevistas de trabajo se le escapa, sufrió abusos y trabajo precario hasta que consiguió un empleo "hecho a su medida" gracias a que pudo conocer al responsable de una sección del ayuntamiento dedicado a la atención de la discapacidad que le contrató nada más conocerle. Sensibles a estas dificultades se ha puesto en marcha una web con el nombre de Solidjobs, donde un equipo "neurodivergente" facilita el acceso al trabajo de la tecnotribu autista.

También merece una mención especial el canal youtube Insurgencia autista en el que podemos escuchar las deliberaciones de adultos autistas -Ana Lía, Ezequiel y Constanza- quienes, con un remarcable sentido del humor, reflexionan sobre su día a día, sobre los malentendidos que ocasionan sus comportamientos en la convivencia con neurotípicos tanto a nivel de pareja, en lo relativo a la maternidad y a la sexualidad. Aprovechan ese medio para razonar sobre los motivos de los sufrimientos padecidos, entre ellos, ante la imposibilidad de expresar un malestar que se manifestaba en una de las chicas como un "chillido constante, eterno"; hoy en día ella es docente, y confiesa el alivio que le proporcionan las clases virtuales, también su colega admite su preferencia por el teletrabajo donde "rendimos mejor" asegura.

Frente a la ansiedad y los ataques de pánico que padecen debido a la "intolerancia a 
lo social" y que les obliga a la ingesta de medicación, el distanciamiento del mundo que aportan los tecnoentornos les proporcionan calma y placer. Es un hecho a celebrar, sin duda. Sin embargo, queda por dilucidar la contribución de este modo de comunicación en la conquista de una identidad sinthomática ${ }^{25}$ que atempere la angustia al otorgarles un lugar, la subjetivación de su cuerpo y una enunciación propia, una vez producido el deshielo de su palabra congelada.

\section{Notas}

1 "De este modo he aprendido indirectamente normas de cortesía que de otra forma me habrían parecido molestas y aburridas” (Schovanec, 2015, p. 38).

${ }^{2}$ Capacitista: término de uso frecuente en la comunidad autista para referirse a los baremos con que se mide su carácter deficitario con la expectativa de que alcanzarán la norma.

${ }^{3}$ Su familia es originaria de Checoeslovaquia, sus padres le protegían de las exigencias justificando sus dificultades en el cambio de entorno lingüístico.

${ }^{4}$ Freud le dedica un estudio especial: Un caso de paranoia ("Dementia paranoides") descrito en forma autobiográfica (caso "Schreber") (Freud, 1913/1973, p. 1487).

${ }^{5}$ J. Lacan, Petit discours aux psychiatres. Inédito.

${ }^{6} \mathrm{Y}$ que puede resumirse en la influencia de tres factores: El desarrollo de las ciencias y las técnicas; los descubrimientos geográficos, la consciencia del yo (Regales Serna, 1998, p. 5).

${ }^{7}$ A Schovanec le impresionó encontrar entre los ocupantes de la nave la figura del erudito.

${ }^{8}$ La nave de los locos, p. 287.

9 “...Después de los Gramáticos, los Poetas, los Rectores y los Escritores; después de los Jurisconsultos; después de ellos vienen los Filósofos (...) y al final los Teólogos”.

10 "Casi todos los hombres desatinan... ¿qué digo? Deliran de mil maneras" (Erasmo, 1509/1993, p. 23).

${ }^{11}$ A diferencia de los otros tres cuya lógica desentrañó en su Seminario XVII El envés del psicoanálisis: el discurso del amo, de la histeria y de la universidad.

${ }^{12}$ Lacan considera esencial la elección de Shakespeare. De hecho "no se trata más que de eso, de saber lo que el loco tiene en la cabeza", afirma.

${ }^{13}$ Parte de este texto en donde despliego mi lectura de la obra fue publicado con el título ¿Cómo hablar con quienes prefieren no hacerlo? en revista la Cause Freudienne No78 Navarin, Paris, 2004, p.27

${ }^{14}$ Según lo explica Lacan en Homenaje a M. Duras, por el arrobamiento de Lol V. Stein (Lacan, 2012, p. 211). 
${ }^{15}$ Lacan definía el mito como "la construcción que consigue dar forma épica a la estructura”, es decir, a lo imposible de ser simbolizado.

${ }^{16}$ Ecoutez les autistes! ¡Escuchen a los autistas! El texto del psicoanalista y profesor de la Universidad de Rennes, Jean-Claude Maleval (2012), constituye un manifiesto frente al tumulto que recorrió Francia, una vez designado el autismo "Gran Causa Nacional 2012". Su pedido recoge la Declaración de los derechos de personas autistas como "el derecho de no ser expuestos a la angustia, a las amenazas de tratamientos abusivos".

${ }^{17}$ V. Coccoz, Tribus urbanas. En www.vilmacoccoz.com

${ }^{18}$ Muchos de ellos incluyen en su nombre de usuario su condición autista y asperger.

${ }^{19}$ Freud (1921/1973, p. 2563) estudia la identificación en la formación del yo y demuestra que "no existe sujeto sin Otro" al afirmar que la psicología individual es, a la vez, social. Como textos de referencia en Lacan (2006), El estadio del espejo como formador del yo [Je] tal como se nos revela en la experiencia psicoanalítica y Observaciones sobre el informe de Daniel Lagache: "Psicoanálisis y estructura de la personalidad".

${ }^{20}$ En su testimonio excepcional Donna Williams (1992) describe el momento de la elección y adopción de las máscaras de Carol y Willie

${ }^{21}$ Je suis Babouillec, "très declarée sans paroles".

22 "La imagen de sí mismo en la mirada de Mr. Nobody" (Léguil, 2018, p. 21).

${ }^{23} \mathrm{~A}$ fin de captar la sutileza de la dimensión topológica fundamental a considerar en el tratamiento del autismo el comentario de un caso por parte de Eric Laurent en el marco del Seminario del Campo Freudiano de Bilbao es paradigmático. Seminario CFBilbao, sesión del 19 de octubre de 2013. También en el documental A cielo abierto se destaca la importancia de este aspecto en los niños acogidos en Courtil.

${ }^{24}$ Asper Revolution, blog.

${ }^{25}$ Identidad sinthomática: noción derivada de la última enseñanza de Lacan que resume el resultado del anudamiento singular entre los tres registros de la experiencia (real, simbólico e imaginario) a través del síntoma considerado como una invención que consigue vincular la existencia al lazo social. 


\section{Referencias}

Baouillec, H. (2018).Algoritme eponyme. Payot \& Rivages.

Coccoz, V. (2021). Freud y la psicosis ordinaria. En su Nuevas formas del malestar en la cultura. Grama.

Coccoz, V. (Comp.) (2013). La práctica lacaniana en instituciones I. Grama.

Coccoz, V. (Comp.) (2017). La práctica lacaniana en instituciones II. Grama.

Deleuze, G., Agamben, G. y Pardo, J. L. (2000). Preferiría no hacerlo. Pre-textos.

Echeverría, J. y Almendros, L. (2020). Tecnopersonas. Cómo las tecnologías nos transforman. Trea.

Erasmo (1509/1993). Elogio de la locura. Libros Río Nuevo.

Foucault, M. (1961/1967). Historia de la locura en la época clásica. Fondo de Cultura Económica.

Freud, S. (1913/1973). Obras completas. Tomo II. Biblioteca Nueva.

Freud, S. (1921/1973). Obras completas. Tomo III. Biblioteca Nueva.

Grandin, T. (2001). Ma vie d'autiste. Odile Jacob.

Lacan, J. (1979). De la psicosis paranoica y sus relaciones con la personalidad. Siglo XXI.

Lacan, J. (1981). Seminario I. Los escritos técnicos de Freud. Paidós.

Lacan, J. (1994). Seminario IV. La relación de objeto y las estructuras freudianas. Paidós.

Lacan, J. (2006). Obras escogidas. RBA Ediciones.

Lacan, J. (2012). Otros escritos. Paidós.

Lacan, J. (2014). Seminario VI. El deseo y su interpretación. Paidós.
Langelez Stevens, K. (2021). L'autisme, la langue et le corps. Intervención en las Jornadas del Cera, $16 / 1 / 2021$.

Laurent, E. (2012). La batalla del autismo. Grama.

Léguil, C. (2018). "Je". Une traversée des identitées. PUF.

Luccheli, J. P. (2020). El objeto autístico no es un objeto a. Psicoanálisis lacaniano. HTTPS:// PSICOANALISISLACANIANO.COM/2020/12/11/ LPLUCCHELLI-OBJETO-AUTISTICO-NO-ESOBJETO-A-20201211/

Maleval, J.-C. (2012). Ecoutez les autistes! Navarin.

Maleval, J.-C. y Grollier, M. (2021). Gel et dégel du S1 chez le sujet autiste. La cause de l'autisme. HTTPS://CAUSE-AUTISME.FR/2021/01/18/GEL-ETDEGEL-DU-S1-CHEZ-LE-SUJET-AUTISTE/

Melville, H. (1987). Bartleby, el escribiente. Biblioteca personal J. L. Borges. Hyspamérica.

Miller, J.-A. (2011). Donc. La lógica de la cura. Paidós.

Miller, J.-A. (2013). El ultimísimo Lacan. Paidós.

Miller, J.-A. (2015). Todo el mundo es loco. Paidós.

Regales Serna, A. (1998). La nave de los necios. Akal.

Schovanec, J. (2015). Yo pienso diferente. Palabra.

Sellin, B. (2011). Quiero dejar de ser un dentrodemí. Galaxia Gutemberg.

Williams, D. (1992). Si on me touche, je n'existe pas. Robert Lafont.

Williams, D. (2012). Alguien en algún lugar. N.E.D.

Zenoni, A. (2009). L'autre pratique clinique. Editions Érès 